\title{
Antenatal diagnosis of oesophageal atresia with tracheoesophageal fistula with upper neck pouch sign-A radiological study
}

\author{
Sangeeta Saxena ${ }^{1}$, Radhey Sankhala ${ }^{2}$, Dharmraj Meena ${ }^{3}$, Aditya Ganeriwala ${ }^{4}$, Devendra Verma ${ }^{5}$ \\ ${ }^{1}$ Dr. Sangeeta Saxena. MD, Professor and Head, Department of Radiodiagnosis, Government Medical College and \\ Associated Group of Hospitals, Kota 324001, ${ }^{2}$ Dr. Radhey Sankhala, Resident Doctor, Department of Radiodiagnosis, \\ Government Medical College and Associated Group of Hospitals, Kota 324001, ${ }^{3}$ Dr. Dharmraj Meena. MD, Associate \\ Professor, Department of Radiodiagnosis, Government Medical College and Associated Group of Hospitals, Kota \\ 324001, ${ }^{4}$ Dr. Aditya Ganeriwala, Resident Doctor, Department of Radiodiagnosis, Government Medical College and \\ Associated Group of Hospitals, Kota 324001, ${ }^{5}$ Dr. Devendra Verma, Resident Doctor, Department of Radiodiagnosis, \\ Government Medical College and Associated Group of Hospitals, Kota 324001.
}

Address for Correspondence: Dr Radhey Sankhla, E-mail: drradhey05@gmail.com

\begin{abstract}
Oesophageal atresia is rare antenatal diagnosis due to absence of clinical and sonographic findings. On antenatal USG, the finding of an absent or small stomach bubble with polyhydramnios is considered suspicious of oesophageal atresia. However, these findings is not confirmative. The upper neck pouch sign is another specific sign that helps in the antenatal diagnosis of oesophageal atresia.
\end{abstract}

Key words: Oesophageal atresia, tracheoesophageal fistula, Upper neck pouch sin.

\section{Introduction}

Oesophageal atresia is a congenital anomaly in which there is interruption of the oesophageal lumen resulting in an upper and lower segment. The diagnosis of oesophageal atresia may be suspected on prenatal ultrasound scan in fetus with a small or absent stomach or unexplained polyhydramnios. However, these findings are thought to have a low positive predictive value and clinical decisions affecting timing or site of delivery may be made erroneously [1]. The all over incidence of tracheoesophageal fistula is 1 in 3000 births [2]. There is no established sex preponderance. Chromosomal, gastrointestinal, and urogenital anomalies are found in $58 \%$ of patients and congenital heart disease in 15-39\% [3-6]. The prognosis of oesophageal atresia depends on four factors: associated congenital malformations, respiratory complications, birth weight, and gestational age at delivery

\section{Case Report}

A 30 year old non-diabetic, non-alcoholic primigravida with normal obstetric examination came for foetal sonography for antenatal care. There was no history of intake of teratogenic drugs and other relevant past illness. Abdominal examination at gynaecology department revealed excessive liquor. During ultrasonographic scan a single live foetus of gestational age of about 32 week was seen with indeterminate presentation. Femur length, abdominal circumference were correlating with gestational age of about 32 weeks. Facial feature were normal with normal inter and intra orbital distance according to gestation, nasal bone and lips were seen normally formed. No appreciated defect and no mass was seen attached or arising from the spine. Intra-abdominal organs were normal. Placenta was anterior in position with normal thickness. The foetus showed normal cardiac activity (136 beats/min) with normal rhythm. The foetal movements were normally coordinated

Manuscript received $10^{\text {th }}$ July 2016

Reviewed: $25^{\text {th }}$ July 2016

Author Corrected: $10^{\text {th }}$ August 2016

Accepted for Publication $24^{\text {th }}$ August 2016 


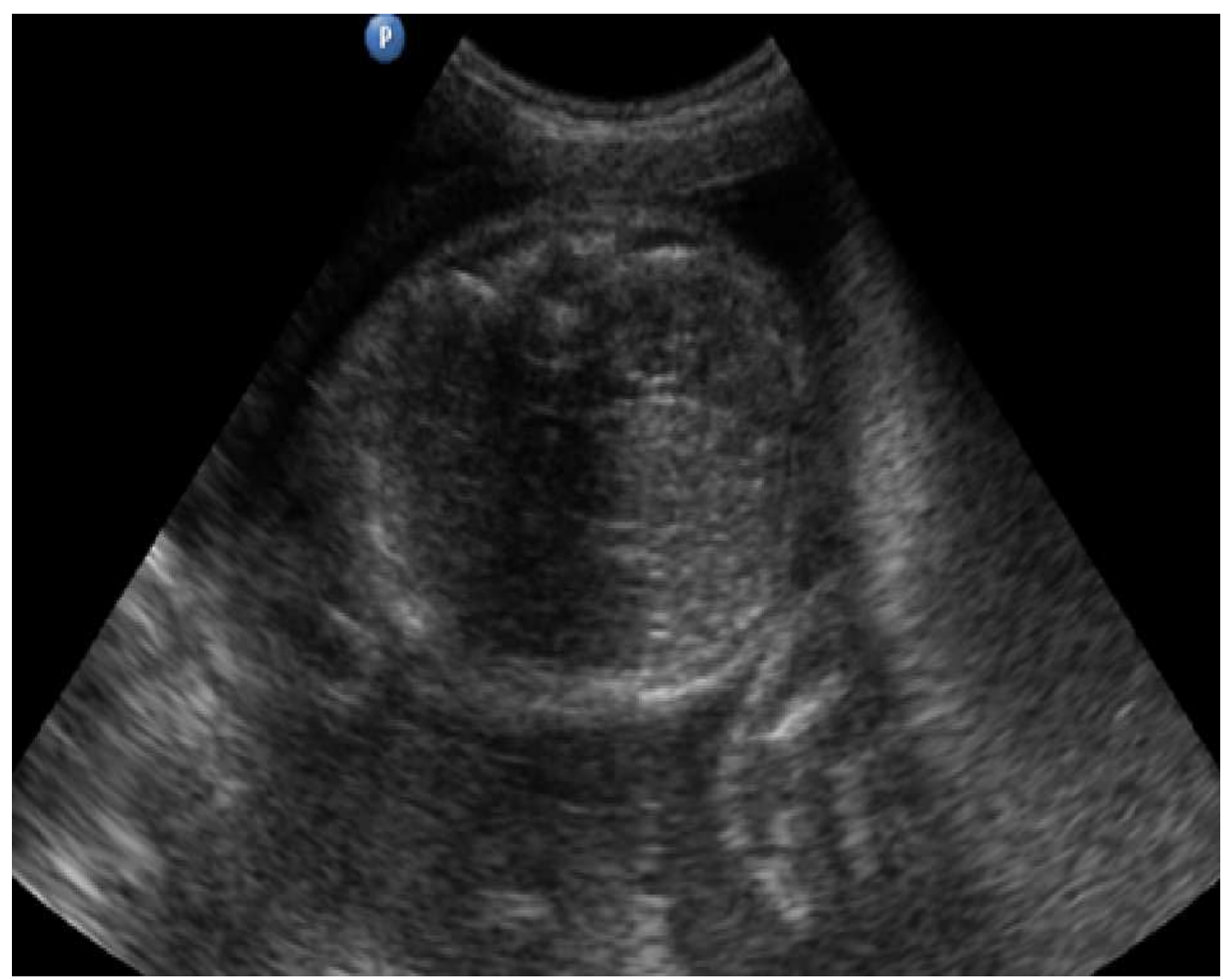

Figure-1: Transverse ultrasound image of fetal abdomen showing absent stomach bubble

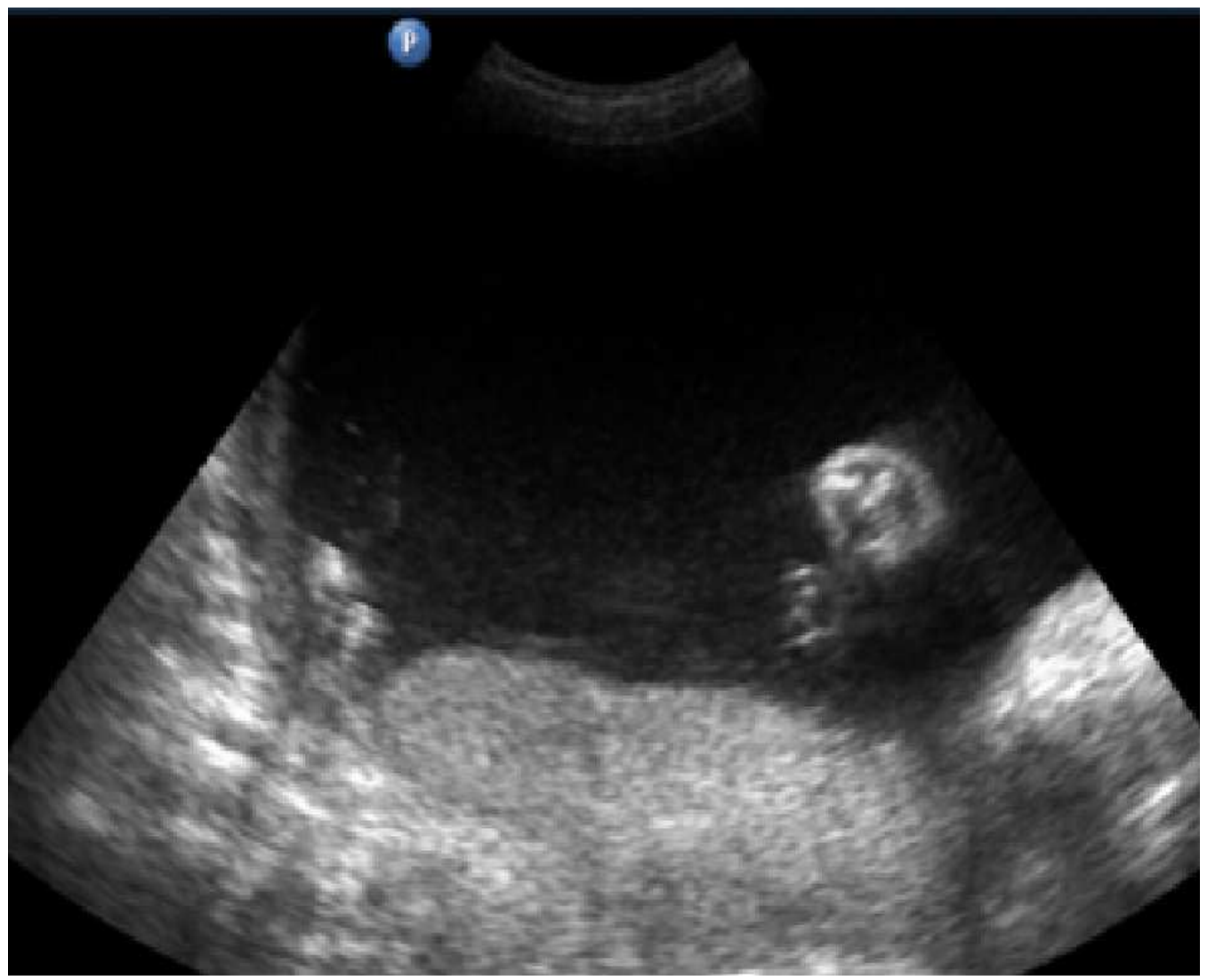

Figure-2: Transverse ultrasound image showing polyhydramnios 


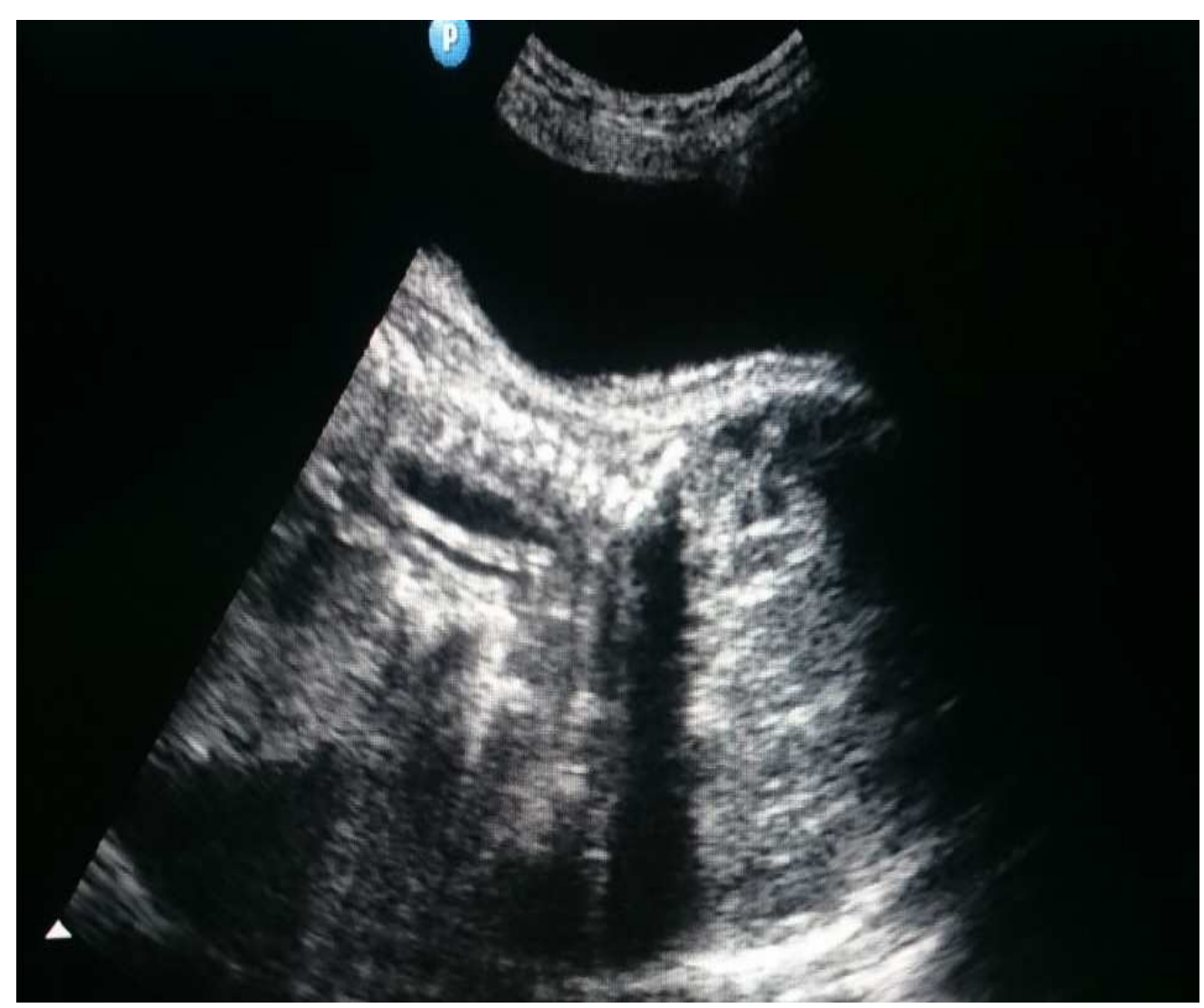

Figure-3: sagittal scan of neck and chest of fetus shows dilated blind-ending proximal oesophagus with tapering distal part (pouch sign) in the full phase.

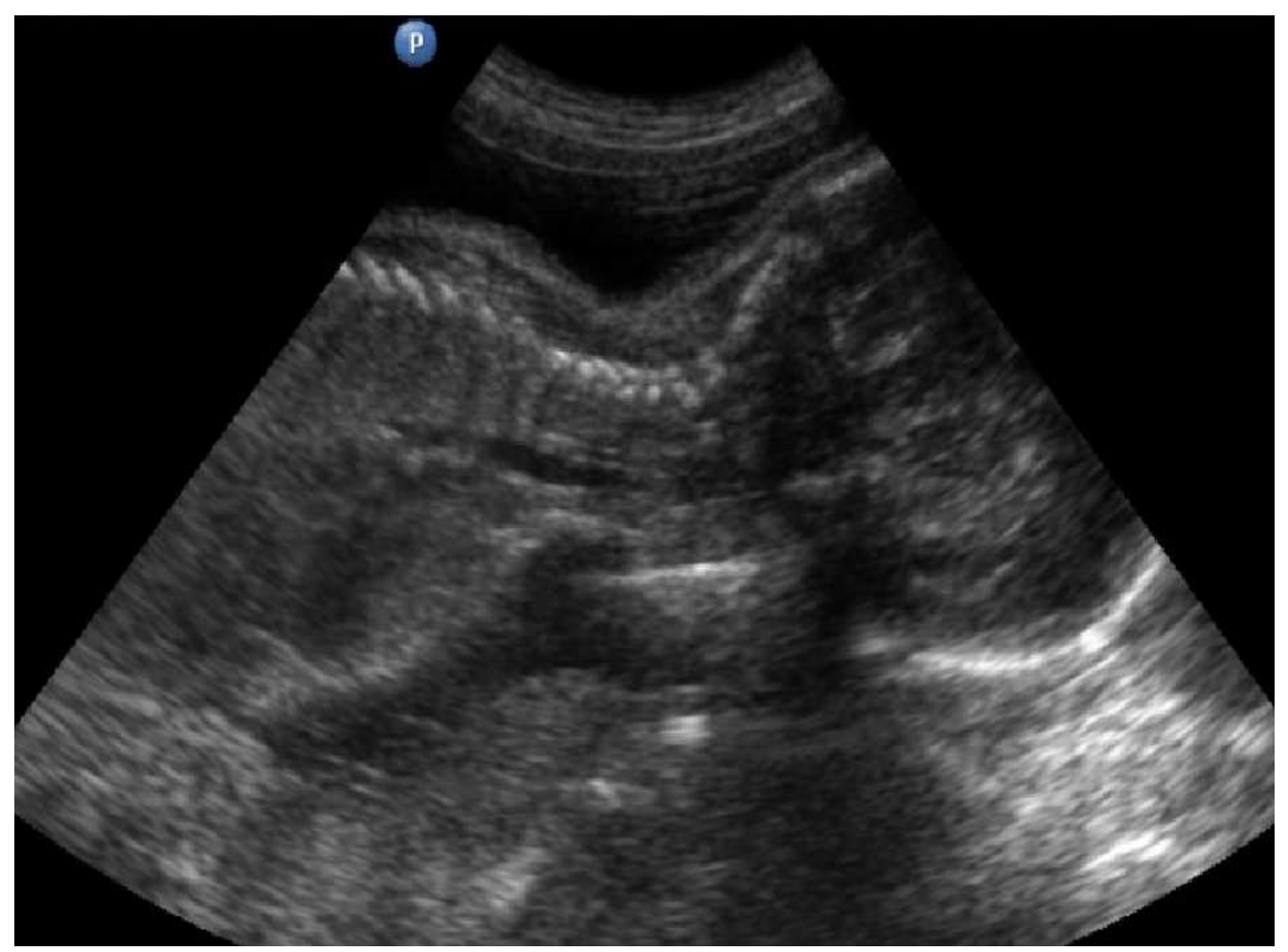

Figure-4: Sagittal section of fetal neck and chest showing the blind-ending proximal oesophagus with tapering distal part (pouch sin) in the empty phase. 


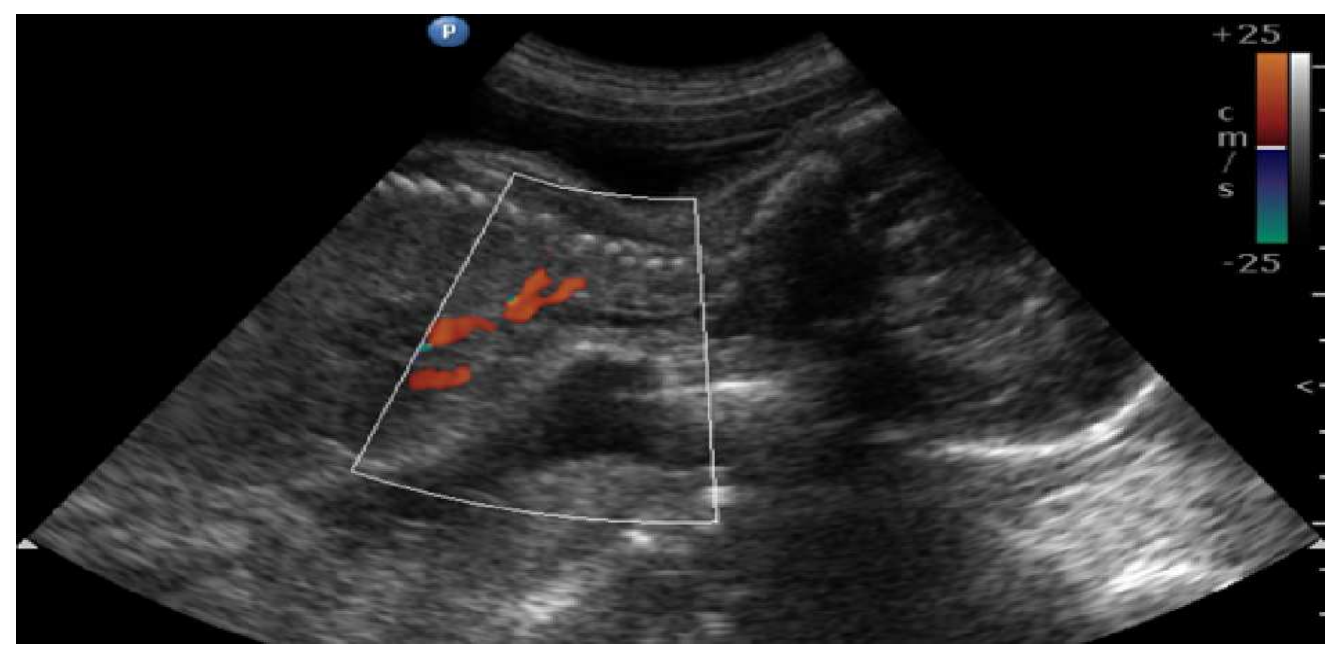

Figure-5: Color Doppler Ultrasound image showing no color flow within the blind-ending pouch of oesophagus.

Excessive liquor (AFI>25) and non-visualization of stomach bubble, raised suspicion of Tracheoesophageal fistula. On detailed examination of fetal neck and thorax, an anechoic, dilated, blind-ending proximal oesophageal pouch with distal tapering end was seen. It revealed alternate filling and emptying on real-time scanning ('upper neck pouch sign'). Based upon this finding, a provisional diagnosis of oesophageal atresia with the presence of a distal tracheoesophageal fistula was made. At follow up scan after 2 week same sonographic findings was seen with normal growing foetus. At 36 weeks of gestation a male baby with $2.5 \mathrm{~kg}$ birth weight was delivered vaginally. Post-natal chest X-ray revealed absence of gastric bubble. On insertion of a nasogastric tube there was coiling of tube in the mediastinum of the neonate. This finding was diagnostic of tracheoesophageal fistula associated with oesophageal atresia. Then patient go for surgery in paediatric surgery department, during surgery oesophageal atresia and tracheoesophageal fistula was detected and corrected by surgery. Then child have uneventful post-operative period.

\section{Discussions}

Oesophageal atresia and tracheoesophageal fistula is a complex congenital fetal anomaly characterized by incomplete formation of tubular oesophagus or an abnormal communication between oesophagus and trachea. The precise cause of this complex is not known but it is thought to be a developmental disorder in the formation and separation of primitive foregut into the trachea and oesophagus [7]. It incidence with or without tracheoesophageal fistula is 1 in $3000-4000$ birth with male predominance.

There are five types of congenital oesophageal atresia and tracheoesophageal fistula. Most common (comprising approximately $88.5 \%$ of case) type is type $\mathrm{C}$, which consists of distal Tracheoesophageal fistula with proximal oesophageal atresia. Gross type A, or isolated oesophageal atresia, occurs in approximately $8 \%$ of cases. Gross type E, consisting of Tracheoesophageal fistula without oesophageal atresia, or H-type Tracheoesophageal fistula, occurs in approximately $4 \%$ of cases, with the remainder consisting of Gross types B and D [8].
Ante-natal diagnosis of oesophageal atresia may be suggested by presence of combination of polyhydramnios along with an absent or small stomach [9]. However, these findings are not conclusive. A moderately distended stomach may be visualized in a case of oesophageal atresia with or without tracheoesophageal fistula as a consequence of retained or increased gastric secretions [10].

Polyhydramnios and an absent or small stomach may be associated with numerous other anomalies, [11] e.g., diaphragmatic hernia or deficient foetal swallowing due to mechanical obstruction, facial clefts or neuromuscular disease.

Polyhydramnios with absent stomach bubble with an anechoic, dilated, blind-ending proximal oesophageal pouch seen in the neck showing alternate filling and emptying on real-time scanning ('upper neck pouch sign') is considered specific for ante-natal diagnosis of oesophageal atresia with tracheoesophageal fistula [12]. Similar findings were seen in our case. 
Antenatal suspicion of oesophageal atresia is usually depend up on the finding of a small or absent foetal stomach bubble in association with polyhydramnios. As similar findings may be seen in other abnormalities, confirmation of the diagnosis is generally not possible until birth [12].

\section{Conclusion}

Careful foetal neck examinations necessary in all cases of polyhydramnios to look for upper neck pouch sign because it is specific for oesophageal atresia with or with-out trachea-oesophageal fistula irrespective of presence or absence stomach bubble.

Funding: Nil, Conflict of interest: None initiated, Permission from IRB: Yes

\section{References}

1. Langer $\mathrm{JC}^{1}$, Hussain H, Khan A, Minkes RK, Gray D, Siegel M, Ryan G. Langer $\mathrm{JC}^{1}$, Hussain H, Khan A, Minkes RK, Gray D, Siegel M, Ryan G. J Pediatr Surg. 2001 May; 36(5):804-7. [pubmed]

2. Beasley SW. Oesophageal atresia without fistula. In Oesophagea Atresia, Beasley S, Myers N, Auldist A (eds). London: Chapman \& Hall Medical, 1991; Chapter 10, 137-159.CrossRef.

3. Nicolaides K, Snijders R, Cheng H. Fetal gastrointestinal and abdominal wall defects: associated malformations and chromosomal abnormalities. Fetal DiagnTher 1992; 7: 102-115.CrossRef| PubMed |CAS |Web of Science® Times Cited: 62.

4. Damato N, Filly R, Goldstein R. Frequency of fetal anomalies in sonographically detected polyhydramnios. J Ultrasond Med 1993; 12: 11-15. PubMed|CAS | Web of Science ${ }^{\circledR}$ Times Cited: 21.
5. Havard A, MacDonald L. Oesophageal atresia and other disorders with a similar antenatal presentation. $\mathrm{Br}$ JRadiol1991; 64: 557-558.CrossRef | PubMed|CAS| Web of Science ${ }^{\circledR}$ Times Cited: 7

6. Ein S, Shandling B, Wesson D. Esophageal atresia with distal tracheoesophageal fistula: associated anomalies and prognosis in the 1980s. J Pediatr Surg 1989; 24: 1055-1059.CrossRef | PubMed|CAS| Web of Science ${ }^{\circledR}$ Times Cited: 48.

7. Cumming WA.Esophageal atresia and tracheaesophageal fistula.Radiol clin north am 1975; 13:277285 , july 1999 volume 19 , issue 4 .

8. Harmon CM, Coran AG. Congenital anomalies of the esophagus.In: O’Neill JA Jr, Rowe MI, Grosfeld JL, eds. Pediatric surgery.St. Louis, MO: Mosby; 1998; 941-967.

9. Hertzberg BS, Bowie JD. Fetal gastrointestinal abnormalities. Radiol Clin North Am. 1990 Jan; 28 (1):101-14.

10. Bovicelli L, Rizzo N, Orsini LF. Prenatal diagnosis and management of fetal gastrointestinal abnormalities. Semin Perinatol 1983; 7:109-11. Indian J Radiol Imaging. 2009 Aug; 19(3): 252-254.doi: 10.4103/09713026.54875 .

11. Houben $\mathrm{CH}$, Curry JI. Current status of prenatal diagnosis, operative management and outcome of esophageal atresia/tracheo-esophageal fistula. Prenat Diagn Feb 272008.

12. Kalache KD, Chaoui R, Mau H. The upper neck pouch sign: A prenatal sonographic marker for esophageal atresia. Ultrasound Obstet Gynecol 1998; 11:138-40. Ultrasound Obstet Gynecol. 1998 Feb; 11 (2):138-40.

\section{How to cite this article?}

Sangeeta Saxena, Radhey Sankhala, Dharmraj Meena, Aditya Ganeriwala, Devendra Verma.Antenatal diagnosis of oesophageal atresia with tracheoesophageal fistula with upper neck pouch sign-A radiological study. Int J Med Res Rev 2016;4(9):1636-1640.doi:10.17511/ijmrr. 2016.i09.21. 